\title{
“Don't Believe Your Eyes" Ipratropium Induced Mydriasis: A Case Report and Review of the Literature
}

Kelly Pennington ${ }^{1}$ and Erik St. Louis ${ }^{2^{*}}$

${ }^{1}$ Department of Internal Medicine, Mayo Clinic, Rochester, USA

${ }^{2}$ Department of Neurology, Mayo Clinic, Rochester, USA

"Corresponding author: Erik St. Louis, Department of Neurology, Mayo Clinic, 200 First Street SW, Rochester, MN 55905, USA, Tel: 507-266-7456; Fax: 507-266-7772; E-mail: StLouis.Erik@mayo.edu

Rec date: April 18, 2016; Acc date: June 22, 2016; Pub date: June 29,2016

Copyright: $\odot 2016$ Pennington, et al. This is an open-access article distributed under the terms of the Creative Commons Attribution License, which permits unrestricted use, distribution, and reproduction in any medium, provided the original author and source are credited.

\begin{abstract}
Unilateral fixed mydriasis can be an ominous sign; however in many cases, it is benign and represents pharmacologic mediated action on the iris dilator or sphincter. Differentiation between pharmacologic mediated anisocoria and physiologic anisocoria can be challenging but may save on costly imaging. An 83 year-old woman was admitted with critical limb ischemia and subsequently developed respiratory failure treated with positive pressure ventilation and ipratropium nebulizers. She was noted to have left unilateral mydriasis without other neurologic deficits. Brain magnetic resonance imaging with MR angiography showed no evidence for a mass lesion or posterior communicating artery aneurysm. Her anisocoria self-resolved within 36 hours after nebulizer treatments were stopped. Ipratropium bromide is one of the most common medications used in the hospital setting and should be consider as a possible etiology when examining patients with unilateral mydriasis in the absence of other neurologic findings.
\end{abstract}

Keywords: Anisocoria; Mydriasis; Iatrogenic; Pharmacology; Ipratropium

\section{Introduction}

Unilateral fixed mydriasis, aka a "blown pupil", is often considered to herald an underlying ominous impending process, raising concern for an acutely evolving space-occupying mass lesion progressing toward uncal herniation.

However, in many cases unilateral mydriasis is benign and due to pharmacologic agents mediating direct action on the iris dilator or sphincter. Medications known to cause mydriasis include atropine, scopolamine, amphetamines, and serotonergic medications.

While systemic medications cause bilateral mydriasis, direct ocular inoculation with topical medications can cause unilateral mydriasis. Sympathetic adrenergic stimulation causes constriction of the iris dilator and subsequent pupillary dilatation; whereas, parasympathetic stimulation mediates iris sphincter and pupillary constriction. Aerosolized ipratropium bromide, a medication that blocks muscarinic acetylcholine receptors, is often used to treat obstructive airway disease.

It has been well described in numerous case reports and case series as causing unilateral mydriasis [1-6], mediating pupillary dilatation through its direct parasympatholytic effect; however, unilateral mydriasis associated with ipratropium remains poorly recognized in the [1,5] hospital setting [7].

We report reversible unilateral mydriasis associated with recent inhaled ipratropium in a patient without other neurologic deficits, and review previously published literature of this phenomenon to describe its chief clinical characteristics.

\section{Case Report}

An 83 year-old woman was admitted for critical limb ischemia and subsequently developed acute respiratory failure treated in the Intensive Care Unit with bilevel positive pressure ventilation and ipratropium/albuterol nebulizations (0.5-2.5 mg) delivered noninvasively via a full face mask every 4 hours. After transfer back to the ward, physical examination demonstrated left pupillary mydriasis unreactive to light and accommodation, as well as incidental left extotropia without limitation of extraocular movement (Figure 1). No other neurologic abnormalities were noted, and the patient was asymptomatic. Nebulizer treatments were discontinued, but anisocoria persisted one day later. Brain magnetic resonance imaging with MR angiography showed no evidence for a mass lesion or posterior communicating artery aneurysm. Within 36 hours following onset, her mydriasis completely resolved. 
Citation: Pennington K, St. Louis E (2016) "Don't Believe Your Eyes" Ipratropium Induced Mydriasis: A Case Report and Review of the Literature. Gen Med (Los Angeles) 4: 255. doi:10.4172/2327-5146.1000255

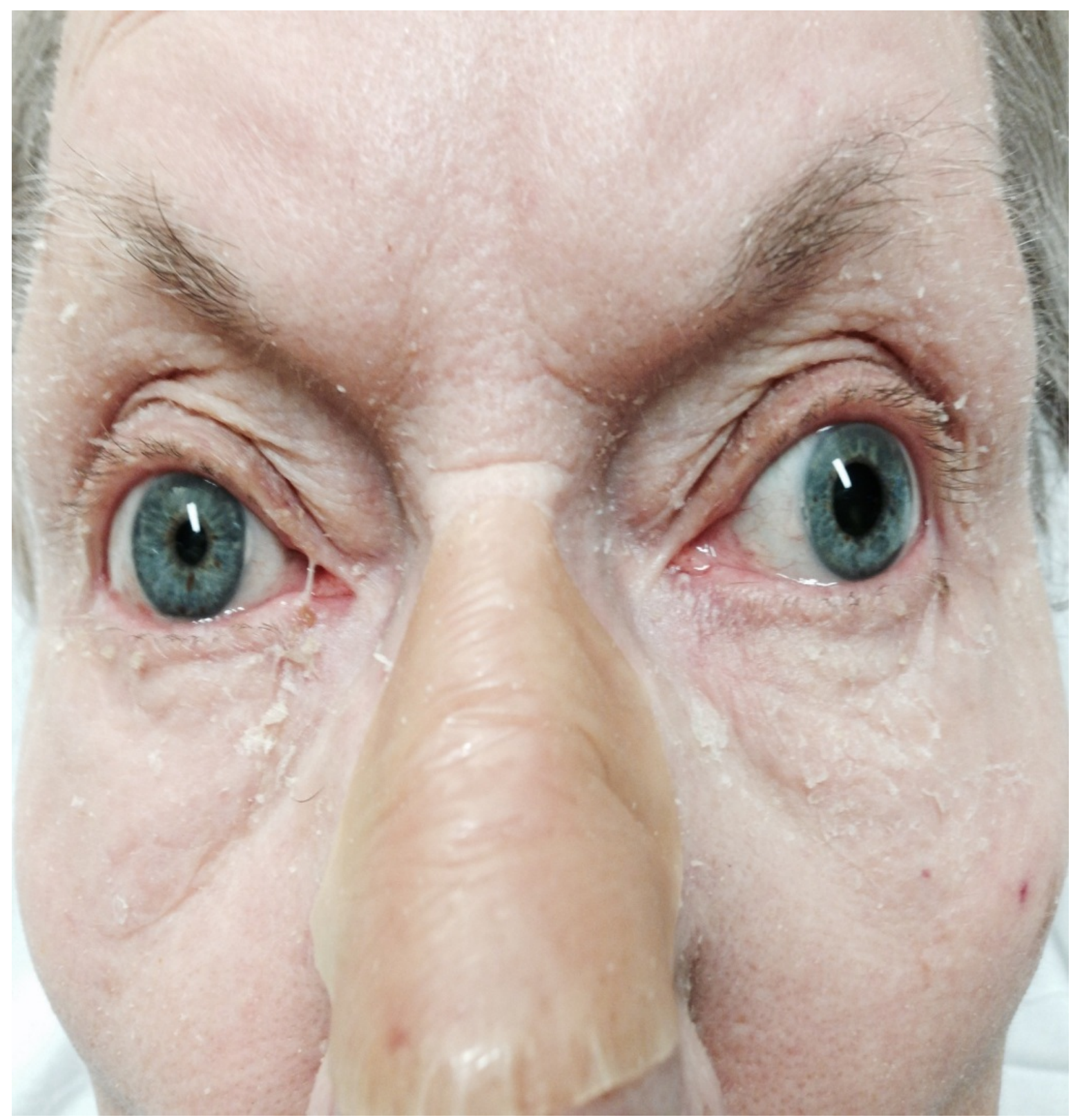

Figure 1: Left mydriasis induced by ipratroium bromide in a 83 year old woman. She had left exotropia due to strabismus, and no weakness of extraocular muscles was observed

\section{Discussion}

Ipratropium bromide is one of the most commonly used medications in the hospital setting, and is being used in conjunction with positive pressure ventilation with increasing frequency. Ipratropium bromide has been known to cause unilateral mydriasis from topical administration secondary to a poorly fitting face mask allowing for medication to directly inoculate one eye [1,3-5,8-10] or broken nebulizer circuit [2]. This phenomenon has been more commonly reported in intensive care and pediatric patient populations, since maintaining proper fitting facemasks may be more challenging in these patients.

We reviewed previously published literature in the English language concerning mydriasis and ipratropium bromide on PubMed between the years of 1986 and 2015, using the search terms "mydriasis, ipratropium bromide" and "anisocoria, ipratropium bromide", and identified 14 articles describing 20 case reports of ipratropium-induced mydriasis in the adult population (Table 1). 
Citation: Pennington K, St. Louis E (2016) "Don't Believe Your Eyes" Ipratropium Induced Mydriasis: A Case Report and Review of the Literature. Gen Med (Los Angeles) 4: 255. doi:10.4172/2327-5146.1000255

Page 3 of 4

\begin{tabular}{|c|c|c|c|c|c|c|}
\hline Age & Sex & Affected Pupil & Duration of affect & $\begin{array}{l}\text { Dosage of } \\
\text { ipratropium }\end{array}$ & Co-morbidities & $\begin{array}{l}\text { Mechanism of ocular } \\
\text { contamination }\end{array}$ \\
\hline 69 & M & Left & Hours & 0.5 mg every 4 hours & $\begin{array}{l}\text { Lung CA, right frontal } \\
\text { craniotomy, left sided facial } \\
\text { weakness and hemiparesis }\end{array}$ & $\begin{array}{l}\text { Facial weakness resulting in } \\
\text { mask leak }\end{array}$ \\
\hline 32 & $\mathrm{~F}$ & Right & $<24$ hours & $\begin{array}{l}\text { Unknown dose every } 4 \\
\text { hours }\end{array}$ & $\begin{array}{l}\text { Left frontal intracerebral } \\
\text { hemorrhage resulting in right } \\
\text { sided hemiparesis }\end{array}$ & $\begin{array}{l}\text { Facial weakness resulting in } \\
\text { mask leak }\end{array}$ \\
\hline 45 & $\mathrm{~F}$ & Right & 8 hours & Unknown & Scrub Typhus Syndrome, Coma & Faulty Nebulizer Circuit \\
\hline 52 & M & Right & $<24$ hours & Unknown & COPD, depression, biliary leak & $\begin{array}{l}\text { BiPap mask with right sided } \\
\text { leak }\end{array}$ \\
\hline 42 & $\mathrm{~F}$ & Right & $<24$ hours & Unknown & $\begin{array}{l}\text { Alcoholic Cirrhosis, Hepatitis B, } \\
\text { Hepatitis C, Fungal Pneumonia }\end{array}$ & $\begin{array}{l}\text { BiPap mask with right sided } \\
\text { leak }\end{array}$ \\
\hline 78 & $\mathrm{~F}$ & Right & 24 hours & Unknown & $\begin{array}{l}\text { Acute myelogenous leukemia, } \\
\text { atrial fibrillation, coronary artery } \\
\text { disease, posterior reversible } \\
\text { encephalopathy syndrome }\end{array}$ & $\begin{array}{l}\text { BiPap mask with right sided } \\
\text { leak }\end{array}$ \\
\hline 64 & M & Left, Right & Hours & $\begin{array}{l}\text { Unknown dose every } 6 \\
\text { hours }\end{array}$ & $\begin{array}{l}\text { Acute lymphoblastic leukemia, } \\
\text { pnuemonia, hydrocephalus }\end{array}$ & Loose fitting facemask \\
\hline 29 & $\mathrm{~F}$ & Right & $<24$ hours & $0.25 \mathrm{mg}$ every 6 hours & Pregnancy & Unknown \\
\hline 36 & M & Left & 48 hours & Unknown & Asthma & Unknown \\
\hline 76 & $\mathrm{~F}$ & Left & 24 hours & Unknown & $\begin{array}{l}\text { Coronary } \quad \text { artery disease, } \\
\text { pneumonia, } \\
\text { accident }\end{array}$ & $\begin{array}{l}\text { Improper facemask use causing } \\
\text { left sided leaking }\end{array}$ \\
\hline 31 & $\mathrm{~F}$ & Left & Unknown & Unknown & Unknown & $\begin{array}{l}\text { Mechanical administration from } \\
\text { contaminated hands }\end{array}$ \\
\hline 22 & $\mathrm{~F}$ & Left & 24 hours & $0.25 \mathrm{mg}$ every 6 hours & Cystic Fibrosis & $\begin{array}{l}\text { Improper facemask use causing } \\
\text { left sided leaking }\end{array}$ \\
\hline 22 & M & Unknown & $36-48$ hours & Unknown & $\begin{array}{l}\text { Acute myelogenous leukemia, } \\
\text { enterrococcal meningitis }\end{array}$ & Unknown \\
\hline 64 & M & Unknown & Unknown & Unknown & $\begin{array}{l}\text { Acute myelogenous leukemia, } \\
\text { alveolar hemorrhage, atrial } \\
\text { fibrillation, renal failure }\end{array}$ & Unknown \\
\hline 42 & M & Unknown & 6 hours & Unknown & $\begin{array}{l}\text { Acute myelogenous leukemia, } \\
\text { alveolar hemorrhage, atrial } \\
\text { fibrillation, renal failure }\end{array}$ & Unknown \\
\hline 40 & M & Unknown & $36-48$ hours & Unknown & $\begin{array}{l}\text { Non-Hodgkins lymphoma, } \\
\text { aspergillus pulmonary infection }\end{array}$ & Unknown \\
\hline 62 & M & Left & 24 hours & Unknown & $\begin{array}{l}\text { Mitral valve replacement, } \\
\text { pneumonia }\end{array}$ & Unknown \\
\hline 68 & M & Unknown & Unknown & Unknown & Cardiac Arrest, coma & Unknown \\
\hline 38 & $\mathrm{~F}$ & Left & Unknown & Unknown & Asthma & Faulty Nebulizer Circuit \\
\hline 24 & $\mathrm{~F}$ & Bilateral & Unknown & High dose & Asthma & Unknown \\
\hline
\end{tabular}

Table 1: Summary of previously reported cases of ipratropium bromide induced anisocoria.

In all reported cases, the affected pupil side was equally represented; and mydriasis was the only new neurologic finding. The reported duration of mydriasis following discontinuation of ipratropium bromide ranged from a few hours to 48 hours with most cases resolving within 24 hours [1-6,8,10-12] and 3 cases taking at least 36 hours for the mydriasis to resolve $[7,11]$. The remainder of the cases did not report duration of the mydriasis. Most cases were attributed to an improperly fitting face mask either from facial weakness [1] or a faulty seal on the mask $[3-5,8,10]$, which we believe was the case in our patient. Faulty nebulizer circuit $[2,13]$, and mechanical contamination of the nebulizer with the eye [9] were also cited as a potential cause. The remainder of the cases did not have a clear etiology. Dosage, 
Citation: Pennington K, St. Louis E (2016) "Don't Believe Your Eyes" Ipratropium Induced Mydriasis: A Case Report and Review of the Literature. Gen Med (Los Angeles) 4: 255. doi:10.4172/2327-5146.1000255

Page 4 of 4

frequency of administration, administration with positive pressure ventilation, and patient specific pharmacokinetics likely play a role in both the induction and duration of mydriasis; unfortunately, this data cannot be gleaned from the current literature.

New onset unilateral mydriasis often raises the concern for an acutely evolving mass lesion such as intracranial hemorrhage, an expanding posterior communicating artery aneurysm (which has particularly close proximity to the third cranial nerve), or tumor leading to uncal herniation; however, mydriasis is rarely the sole neurologic symptom or finding. Moreover confirmatory testing with pilocarpine administration (which demonstrates pupillary constriction in non-pharmacologic etiologies but failure to constrict when the cause is an iatrogenic pharmacologic agent) can also confirm a diagnosis of pharmacologically induced mydriasis and potentially obviate need for imaging [14,15]. However, ophthalmologic consultation is often not promptly available in an inpatient setting when the clinical question arises. Persistent fixed mydriasis beyond the most commonly reported timeframe for pharmacologic causes also suggested necessity for neuroimaging to exclude a compressive mass lesion, as in our case.

\section{Acknowledgments}

The project described was supported by the National Center for Research Resources and the National Center for Advancing Translational Sciences, National Institutes of Health, through Grant Number 1 UL1 RR024150-01. The content is solely the responsibility of the authors and does not necessarily represent the official views of the NIH.

\section{References}

1. Chaudhry P, Friedman DI, Yu W (2014) Unilateral pupillary mydriasis from nebulized ipratropium bromide: A false sign of brain herniation in the intensive care unit. Indian Journal of Critical Care Medicine: Peerreviewed, Official Publication of Indian Society of Critical Care Medicine 18: 176-177.
2. Parmar KK, Dwaram S, Chacko B (2009) Mydriasis in a critically ill patient. Anaesthesia and Intensive Care 37: 861-862.

3. Wehbe E (2008) Transient anisocoria caused by aerosolized ipratropium bromide exposure from an ill-fitting face mask. Journal of Neuroophthalmology: The Official Journal of the North American Neuroophthalmology Society 28: 236-237.

4. Iosson N (2006) Images in clinical medicine. Nebulizer-associated anisocoria. The New England Journal of Medicine 354: e8.

5. Bisquerra RA, Botz GH, Nates JL (2005) Ipratropium-bromide-induced acute anisocoria in the intensive care setting due to ill-fitting face masks. Respiratory Care 50: 1662.

6. Lust K, Livingstone I (1998) Nebulizer-induced anisocoria. Annals of Internal Medicine 128: 327.

7. Santana-Cabrera L (2012) Unilateral mydriasis secondary to ipratropium bromide in a critically ill patient. Journal of Emergencies, Trauma, and Shock 5: 199-200.

8. Camkurt MA (2011) Pharmacologic unilateral mydriasis due to nebulized ipratropium bromide. The American Journal of Emergency Medicine 29: 576.e5-576.e6.

9. Murphy AP, Cusack S, McCarthy G (2010) Blindingly obvious-Combivent as a cause of a unilateral painless mydriasis. Irish Medical Journal 103: 156-157.

10. Sharma NS (2008) Pharmacological mydriasis secondary to ipratropium bromide: a cause of unilateral dilated pupil. Journal of Clinical Neuroscience: Official Journal of the Neurosurgical Society of Australasia 15: 320-321.

11. Openshaw $\mathrm{H}$ (2006) Unilateral mydriasis from ipratropium in transplant patients. Neurology 67: 914.

12. Eustace N (2004) Nebulised ipratropium causing a unilateral fixed dilated pupil in the critically ill patient: a report of two cases. Critical Care and Resuscitation: Journal of the Australasian Academy of Critical Care Medicine 6: 268-270.

13. Krovvidi HP, Thillaivasan A (2008) A benign cause for a unilateral dilated pupil in a critical care patient. European Journal of Anaesthesiology 25: 692-693.

14. Samaniego FLS, Newman LS (1986) Migratory anisocoria--a novel clinical entity. The American review of respiratory disease. 134: 844.

15. Alotaibi MA, Wali SO (2014) Anisocoria with high dose ipratropium bromide inhaler. Saudi Medical Journal 35: 508-509. 